\title{
Influence of dentistry procedures on masticatory function of dentate patients
}

\author{
Lucas do Nascimento Tavares, DDS, MSc'1, Karla Zancope, DDS, MSc, PhD'1 , Frederick Khalil Karam, DDS, MSc'1, \\ Wilson Mestriner Júnior, DDS, MSc, PhD², Flávio Domingues das Neves, DDS, MSc, PhD ${ }^{1}$
}

${ }^{1}$ Department of Occlusion, Fixed Prosthodontics and Dental Materials, School of Dentistry, Federal University of Uberlândia, Uberlândia, MG, Brazil

${ }^{2}$ Department of Pediatric Clinics, Preventive and Social Dentistry, Faculty of Dentistry of Ribeirão Preto, University of São Paulo, Ribeirão Preto, SP, Brazil

Received for publication: February 20, 2017 Accepted: May 3, 2017

Correspondence to: Prof. Dr. Flávio Domingues das Neves Av. Pará, 1720, Bloco 4L, Anexo A sala 4LA-42 Campus Umuarama, CEP: $38405-320$

Uberlândia, Minas Gerais, Brazil

E-mail: flaviodominguesneves@gmail.com Phone: +55-34-3225-8105 Fax: +55-34-3225-8105

\begin{abstract}
Aim: Evaluate the masticatory performance in patients with different clinical situations: patients with natural dentition without restorative and/or orthodontic intervention (Group CG) and patients with restorations and/or orthodontic intervention (Group TG). Subjects received instruction before the experiment, related to masticatory movements. Methods: Three capsules containing the granules were delivered separately to chew for 20 seconds each, controlled by the examiner. One capsule was chewed for 20 seconds only on the left side; the second capsule was chewed for 20 seconds only on the right side; and the third capsule was chewed for 20 seconds to simulate each patient's mastication. The mean data and standard deviation of masticatory function of each patient was calculated. Results: The results obtained in this study showed that there were no statistically significant differences $(P<0.05)$ between both tested groups $(0.0320 \pm 0.00716,0.0436 \pm$ 0.00974). Conclusions: Patients who were submitted to orthodontic and/or restorative procedures, with balanced occlusion could be used as a control group, making easier the patient recruitment. Clinicians and researchers on masticatory performance evaluation could apply the colorimetric method. The colorimetric method was a standardize method, effective and easy to execute.
\end{abstract}

Keywords: Mastication. Colorimetry. Dentition, Permanent.

\section{Introduction}

The objective of oral rehabilitation is to reestablish phonetics, aesthetics and regular function. A healthy individual must have harmony between the stomatognathic system components; therefore, the knowledge of components of this complex system is extremely important to restore one of the most significant human function, the mastication $^{1-3}$. It is crucial to evaluate correctly chewing function to determinate the quality of a treatment ${ }^{4-8}$.

The orthodontic treatment prioritizes function and occlusion for treatment the patient that has malocclusion, and this should be explained before initiating the treatment ${ }^{9}$. Previous study ${ }^{10}$ demonstrated that 80 per cent of the individuals that attend orthodontic practices disregard structural or functional consideration, could influence in your chewing, masticatory performance, including bite force, occlusal contact area, number of functional tooth units and malocclusion severity ${ }^{11}$. This treatment will assist the patient during your chewing, because the mastication is the first step in the process of digestion ${ }^{12,13}$. 
Obtaining the mean values of masticatory performance of a control group is important for defining a deadline. Previous literature6 described the control group as total dentate patients without signs or symptoms of traumatic occlusion, which have not undergone restorative and/or orthodontic procedures. However, even with advances in preventive dentistry, it has been difficult to recruit patients with these specific characteristics, especially the patients that have not undergone restorative and/ or orthodontic procedures, because most of these patients today already passed by these procedures.

The aim of this study was to evaluate the colorimetric method and the masticatory performance in patients with different clinical situations: patients with natural dentition without restorative and/or orthodontic intervention and patients with restorations and/or orthodontic intervention, using visible spectrophotometry to check for differences between groups. The tested hypothesis was that there is no difference in the masticatory performance when restorative and/or orthodontic interventions are performed.

\section{Material and methods}

The study was submitted to the Ethics Committee in Research of the Federal University of Uberlândia (307.001/13 $\mathrm{CEP} / \mathrm{UFU}$ ) and approved. Twenty patients were selected for this study, after authorization from each patient, expressed in term of Informed Consent. The sample calculation was conducted (SigmaPlot 12.0 for Windows program, Systat Software Inc, USA), considering the expectation of the mean difference equal to 0.70 , the expectation of a standard deviation of 0.80 , the study power $(1-\beta)$ of 0.80 and type I error $(\alpha)$ equal to $0.05^{14}$. The test estimated a minimum sample size of 20 units $(n=20)$ in each group.

Inclusion and exclusion criteria were developed in order to properly select the patients who would go through the research. The control group (Group CG) was composed by adult patients with good general health, complete natural dentition (up to 2nd molar), without any restorative and/ or orthodontic procedures and without signs or symptoms of traumatic occlusion or malocclusion, Angle class I and mesofacial. The test group (Group TG) was composed by adult patients with good general health, complete natural dentition, but submitted to restorative (maximum extension until resin restorative for class II MOD) and/ or orthodontic intervention and without signs or symptoms of traumatic occlusion or malocclusion, Angle class I and mesofacial.

The simulator food ${ }^{15}$ used was standardized with $1 \mathrm{~mm}$ diameter size (Fig. 1). Approximately 245-250 mg of pigmented granules are placed in a $10 \mathrm{~mm}$ PVC rectangular capsule, welded by radiofrequency. Subjects received instruction before the experiment, related to masticatory movements. Three capsules containing the granules were delivered separately to chew for 20 seconds each, controlled by the examiner (Fig. 2). One capsule was chewed for 20 seconds only on the left side; the second capsule was chewed for 20 seconds only on the right side; and the third capsule was chewed for 20 seconds to simulate each patient's mastication. If the capsule ruptured during the experiment, it was discarded and a new capsule was performed.

During mastication, the granules were broken and fuchsin dye was diffused into the capsule, according to the masticatory performance. The contents of the capsule were dissolved in $5 \mathrm{ml}$ of water under continuous vibratory motion for 30 seconds. The solution was then filtered to remove the unbroken granules and the fuchsin solution was analyzed, based on the linear equation of the calibration curve. The fuchsin concentration was measured using a spectrophotometer (Beckman DU-7 UV, Beckman Inc., Palo Alto, CA, USA). The viewable area of the absorbance spectrum at $546 \mathrm{~nm}$ with fuchsin wavelength was defined as the standard calibration curve $(0-12.5 \mathrm{mg} / \mathrm{mL})$.

The mean data and standard deviation of masticatory function of each patient was calculated. The results were tabulated and analyzed by t-test $(\alpha=.05)$. Statistical correlation analysis was performed using a statistical program (SigmaPlot 12.0 for Windows program, Systat Software Inc, San Jose; C.A.; USA).

\section{Results}

The results obtained in this study demonstrated that both tested groups were not statistically different $(\mathrm{p}<0.108)$, according to Figure 3.

For each group, the mean data and standard deviation was described in Table 1.

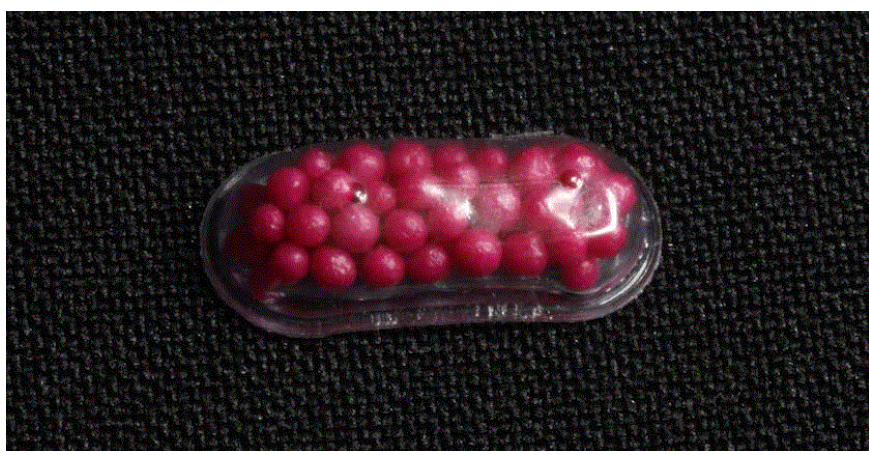

Fig.1. Rectangular capsule containing an acid fuchsin pigment.

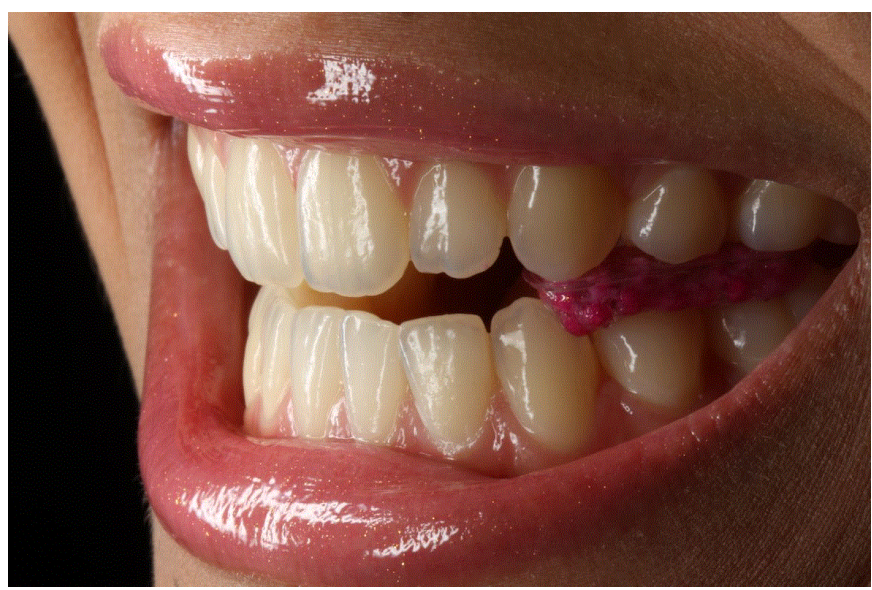

Fig.2. Completely toothed patient chewing the capsule. 


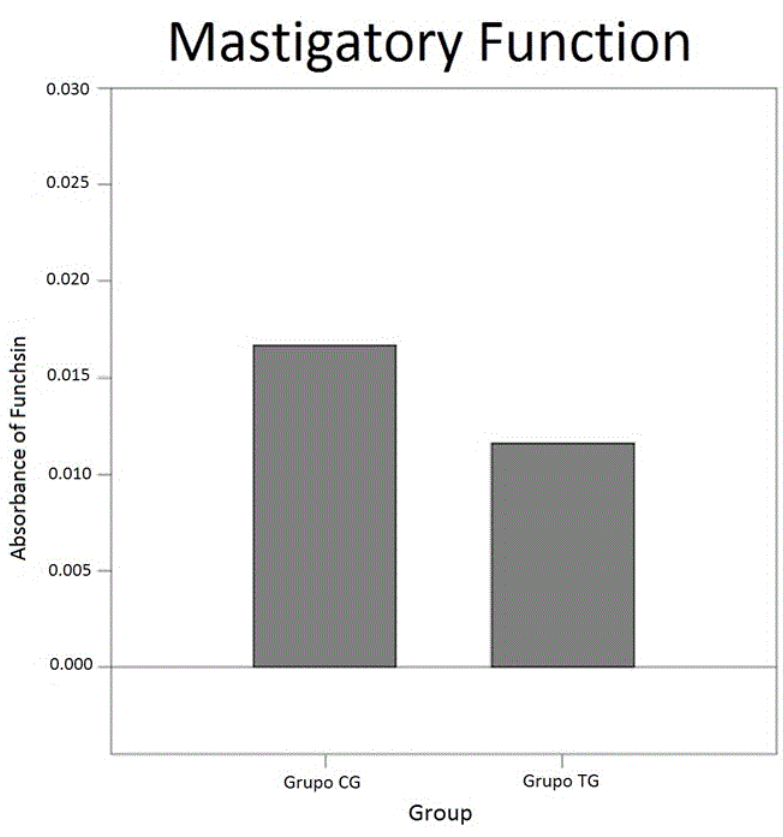

Fig.3. Mean data graphic and standard deviation of the groups and level of absorbance of fuchsin.

Table 1 - Mean data and standard deviation of absorbance of fuchsin release of the tested groups.

\begin{tabular}{cc}
\hline Group CG & Group TG \\
\hline $0.0320 \pm 0.00716 \mathrm{~A}$ & $0.0436 \pm 0.00974 \mathrm{~A}$ \\
\hline
\end{tabular}

Different upper case letters represent significant differences $(\alpha=0.05)$.

\section{Discussion}

The tested hypothesis was confirmed, since there was no difference in the masticatory performance when patients were submitted to restorative (maximum extension until resin restorative for class II MOD) and/ or orthodontic intervention and without signs or symptoms of traumatic occlusion or malocclusion, Angle class I and mesofacial. This study confirms that restorative and/or orthodontic procedures could be performed, and do not affect the masticatory function. It is important to emphases that all tested patients did not present signs or symptoms of traumatic occlusion or malocclusion. A correctly balanced/adjusted occlusion is essential to determine the mean data of the control group.

The colorimetric method was effective, easily to execute and the fuchsin capsule is standardize. All capsules have the same containing. It is possible to storage the capsule for a period of time, even after the masticatory test. It is an advantage over other objective masticatory function methods ${ }^{16-18}$. The application of this standardized methodology is suggested to perform comparison between future studies ${ }^{19}$.

To accomplish some types of clinical studies it is necessary select patients for the control group, where they will be considered standard gold, was composed by adult patients with good general health, complete natural dentition (up to 2nd molar), without any restorative and/ or orthodontic procedures and without signs or symptoms of traumatic occlusion or malocclusion ${ }^{12}$, but this type of patient is rare. Therefor, the results showed that adult patients who participated the study with good general health, complete natural dentition, but submitted to restorative (maximum extension until resin restorative for class II MOD) and/ or orthodontic intervention and without signs or symptoms of traumatic occlusion or malocclusion, does not affect your performance masticatory.

Within the limitations of this study, restorative (maximum extension until resin restorative for class II MOD) and/ or orthodontic intervention in patients without signs or symptoms of traumatic occlusion or malocclusion, Angle class I and mesofacial patients, do not masticatory performance evaluation. The method used was effective and easy to execute.

\section{References}

1. Boretti G, Bickel M, Geering $A H$. A review of masticatory ability and efficiency. J Prosthet Dent. 1995 Oct;74(4):400-3.

2. Scudine KG, Pedroni-PereiraA, Araujo DS, Prado DG, Rossi AC, Castelo PM. Assessment of the differences in masticatory behavior between male and female adolescents. Physiol Behav. 2016 Sep 1;163:115-22. doi: 10.1016/j.physbeh.2016.04.053.

3. Laird MF, Vogel ER, Pontzer H. Chewing efficiency and occlusal functional morphology in modern humans. J Hum Evol. 2016 Apr;93:1-11. doi: 10.1016/j.jhevol.2015.11.005.

4. Jacobsen HC, Wahnschaff F, Trenkle T, Sieg P, Hakim SG. Oral rehabilitation with dental implants and quality of life following mandibular reconstruction with free fibular flap. Clin Oral Investig. 2016 Jan;20(1):187-92. doi: 10.1007/s00784-015-1487-3.

5. Mendonça DB, Prado MM, Mendes FA, Borges TF, Mendonça G, Prado $\mathrm{CJ}$, et al. Comparison of masticatory function between subjects with three types of dentition. Int J Prosthodont. 2009 Jul-Aug;22(4):399-404.

6. Toman M, Toksavul S, Saracoglu A, Cura C, Hatipoglu A. Masticatory performanceand mandibular movement patterns of patients with natural dentitions, complete dentures, and implant-supported overdentures. Int J Prosthodont. 2012 Mar-Apr;25(2):135-7.

7. Giannakopoulos NN, Wirth A, Braun S, Eberhard L, Schindler HJ, Hellmann D. Effect of the occlusal profile on the masticatory performance of healthy dentate subjects. Int J Prosthodont. 2014 Jul-Aug;27(4):383-9. doi: $10.11607 /$ ijp.3793.

8. Pereira LJ, van der Bilt A. The influence of oral processing, food perception and social aspects on food consumption: a review. J Oral Rehabil. 2016 Aug;43(8):630-48. doi: 10.1111/joor.12395.

9. Josefsson E, Bjerklin K, Lindsten R. Factors determining perceived orthodontic treatment need in adolescents of Swedish and immigrant background. Eur J Orthod. 2009 Feb;31(1):95-102. doi: 10.1093/ejo/ cjn069.

10. Baldwin DC. Appearance and aesthetics in oral health. Community Dent Oral Epidemiol. 1980;8(5):244-56.

11. N'gom PI, Woda A. Influence of impaired mastication on nutrition. J Prosthet Dent. 2002 Jun;87(6):667-73.

12. van der Bilt A, Engelen L, Pereira LJ, van der Glas HW, Abbink JH. Ora physiology and mastication. Physiol Behav. 2006 Aug;89(1):22-7.

13. Olthoff LW, Van der bilt A, Bosman F, Kleizen HH. Distribution of particle sizes in food comminuted by human mastication. Arch Oral Biol. 1984;29(11):899-903.

14. Paolantonio M, Perinetti G, Dolci M, Perfetti G, Tetè S, Sammartino G, et al. Surgical treatment of periodontal intrabony defectswith calcium sulfate implant and barrier versus collagen barrier or open flapdebridement alone: a 12-month randomized controlled clinical trial. J Periodontol. 
2008 Oct;79(10):1886-93. doi: 10.1902/jop.2008.080076.

15. Escudeiro Santos C, de Freitas O, Spadaro AC, Mestriner-Junior W. Development of a colorimetric system for evaluation of the masticatory efficiency. Braz Dent J. 2006;17(2):95-9.

16. Van der Bilt A, Fontijn-tekamp FA. Comparison of single and multiple sieve methods for the determination of masticatory performance. Arch Oral Biol. 2004 Mar;49(3):193-8.

17. Schimmel M, Christou P, Herrmann F, Müller F. A two-colour chewing gum test for masticatory efficiency: development of different assessment methods. J Oral Rehabil. 2007 Sep;34(9):671-8.

18. Tarkowska A, Katzer L, Ahlers MO. Assessment of masticatory performance by means of a color-changeable chewing gum. J Prosthodont Res. 2017 Jan;61(1):9-19. doi: 10.1016/j.jpor.2016.04.004.

19. Silva OM, Zancopé K, Mestriner Júnior W, Prado CJ, Neves FD, Simamoto-Junior PC. Masticatory function evaluation by two methods: Colorimetric and sifters. Rev Odontol Bras Central. 2011;20(53):125-8. 